\title{
Pressure-Induced Alopecia: Presence of Thin Hairs as a Trichoscopic Clue for the Diagnosis
}

\author{
Violeta Duarte Tortellya, b Daniel Fernandes Melo ${ }^{a, b} \quad$ Beatriz Serafim Ghedin ${ }^{a}$ \\ Caren dos Santos Limac ${ }^{c}$ Thais Ura Garcia ${ }^{a}$ Taynara de Mattos Barreto ${ }^{a}$ \\ ${ }^{a}$ Department of Dermatology, Marcílio Dias Hospital, Rio de Janeiro, Brazil; ${ }^{b}$ Department of Dermatology, Pedro

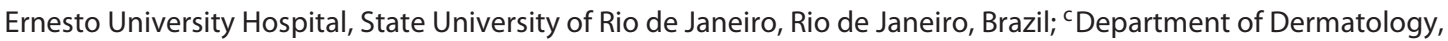 \\ State University of Pará, Belém, Brazil
}

\section{Established Facts}

- Pressure-induced alopecia (PA) is a term used to describe a group of scarring and nonscarring alopecias that usually occur following prolonged immobilization.

- Trichoscopic findings described in the literature are scarce, nonspecific, and include black dots, broken hairs, circle hairs, erythema, and ulcerations.

- Hair loss happens because of tissue ischemia caused by prolonged pressure on the scalp, which results in compression of the vessels surrounding hair follicles with the cessation of their activity.

\section{Novel Insights}

- We report 3 cases of PA in which vellus hairs and residual thin hairs were preserved.

- Since vellus and thin hair bulbs are located more superficially than the terminal ones, they will experience less injury and hypoxia, leading to preservation of those hair shafts. A possible reason would be that the pressure distribution occurs in a conical shape, similar to what happens in pressure ulcers, so it exposes deeper tissues to a higher pressure, leading these areas to suffer more from ischemia.

- We suggest that the presence of thin and vellus hairs should be considered as a trichoscopic clue for PA diagnosis in doubtful cases.

\section{Keywords}

Trichoscopy · Alopecia · Pressure-induced alopecia

\begin{abstract}
Pressure-induced alopecia (PA) is an unusual pattern of circumscribed hair loss that occurs after ischemic changes on the scalp. Trichoscopic findings described in the literature are scarce, nonspecific, and include black dots, broken hairs, circle hairs, and erythema. However, we report 3 cases of PA
\end{abstract}

in which trichoscopy also showed many vellus and thin hairs. Possibly, the maintenance of these hair shafts may be explained by the more superficial insertion of their bulbs on the skin and/or their lower metabolic rates, making them suffer less from local hypoxia. Therefore, the authors suggest that these relevant signs should be added as a clue for the diagnosis of PA in doubtful cases.

(c) 2019 S. Karger AG, Basel

Institute where the work was conducted: Department of Dermatology, Marcílio Dias Naval Hospital.

\section{KARGER}

(c) 2019 S. Karger AG, Basel

E-Mail karger@karger.com

www.karger.com/sad
Violeta Duarte Tortelly

Department of Dermatology, Marcílio Dias Hospital

Boulevard 28 de setembro, 77, Vila Isabel

Rio de Janeiro, RJ 20551-030 (Brazil)

E-Mail violetatortelly@yahoo.com.br 


\section{Introduction}

Pressure-induced alopecia (PA), also known as postoperative alopecia, is a term used to describe a group of scarring and nonscarring alopecias that usually occur following prolonged immobilization, such as long-lasting surgeries or hospitalization in intensive care units (ICUs) $[1,2]$. Hair loss happens because of tissue ischemia caused by prolonged pressure on the scalp, which results in compression of the vessels surrounding hair follicles with the cessation of their activity [2-4].

Clinically, PA presents as a patch of alopecia, in areas corresponding to the basis of the position the head was in during immobilization [5]. Trichoscopic features are nonspecific but sometimes may help in the diagnosis [3, $4,6]$. The prognosis is often good, and the condition is reversible if recognized early [1].

We report 3 cases of PA in which trichoscopy showed residual thin hairs and vellus hairs in the patch. To the best of our knowledge, regarding PA, these findings have not yet been reported in the literature but may be useful in the differential diagnosis with other alopecias.

\section{Case 1}

A 2-year-old Caucasian boy presented with a patch of alopecia in the right parieto-occipital area 15 days after a hypospadias correction surgery. The procedure was performed under general anesthesia, and the patient remained immobilized for $9 \mathrm{~h}$ over a headrest corresponding to the area of hair loss. On physical examination, he had a geometric well-delimited erythematous patch of alopecia, measuring about $8 \times 5 \mathrm{~cm}$ (Fig. 1a). The hair pull test was negative in the lesion and its periphery. Trichoscopy showed discrete erythema, multiple broken hairs with the same length, sparse black dots, and diffuse residual thin and vellus hairs. We saw no yellow dots or exclamation mark hairs (Fig. 2a). Spontaneous hair regrowth was observed at a follow-up 6 weeks later.

\section{Case 2}

A 45-year-old Caucasian woman had a hiatal hernia repair that lasted $12 \mathrm{~h}$ to be performed. Two weeks later, she presented a $5 \times$ $10 \mathrm{~cm}$ round alopecia patch in the occiput (Fig. $1 \mathrm{~b}$ ). The hair pull test was negative in the lesion. In trichoscopy, we observed mild erythema, broken hairs, vellus and residual thin hairs, rare black dots, and some short regrowing hairs (Fig. 2b). Spontaneous hair regrowth started 8 weeks later.
Fig. 1. Clinical findings. a 2-year-old boy with a geometric well-delimited erythematous patch of alopecia in the right parietooccipital area, measuring $8 \times 5 \mathrm{~cm}$. b Round alopecia patch of $5 \times 10 \mathrm{~cm}$ in the occiput of a 45-year-old woman. c 33-year-old man presenting a well-delimited atrophic alopecia patch in the occipital region, measuring $4 \mathrm{~cm}$ in diameter.

Fig. 2. Trichoscopic findings. a Presence of discrete erythema, multiple broken hairs with the same length, sparse black dots, and diffuse residual thin and vellus hairs. b Note the greater amount of broken hairs, vellus and residual thin hairs, and some short regrowing hairs. c Intense and diffuse erythema with a whitish cicatricial area. Some vellus and residual thin hairs can be observed in the periphery of the patch. Dermoscopy performed with 3Gen DermLite $^{\circledR} 4 ; \times 10$ magnification.
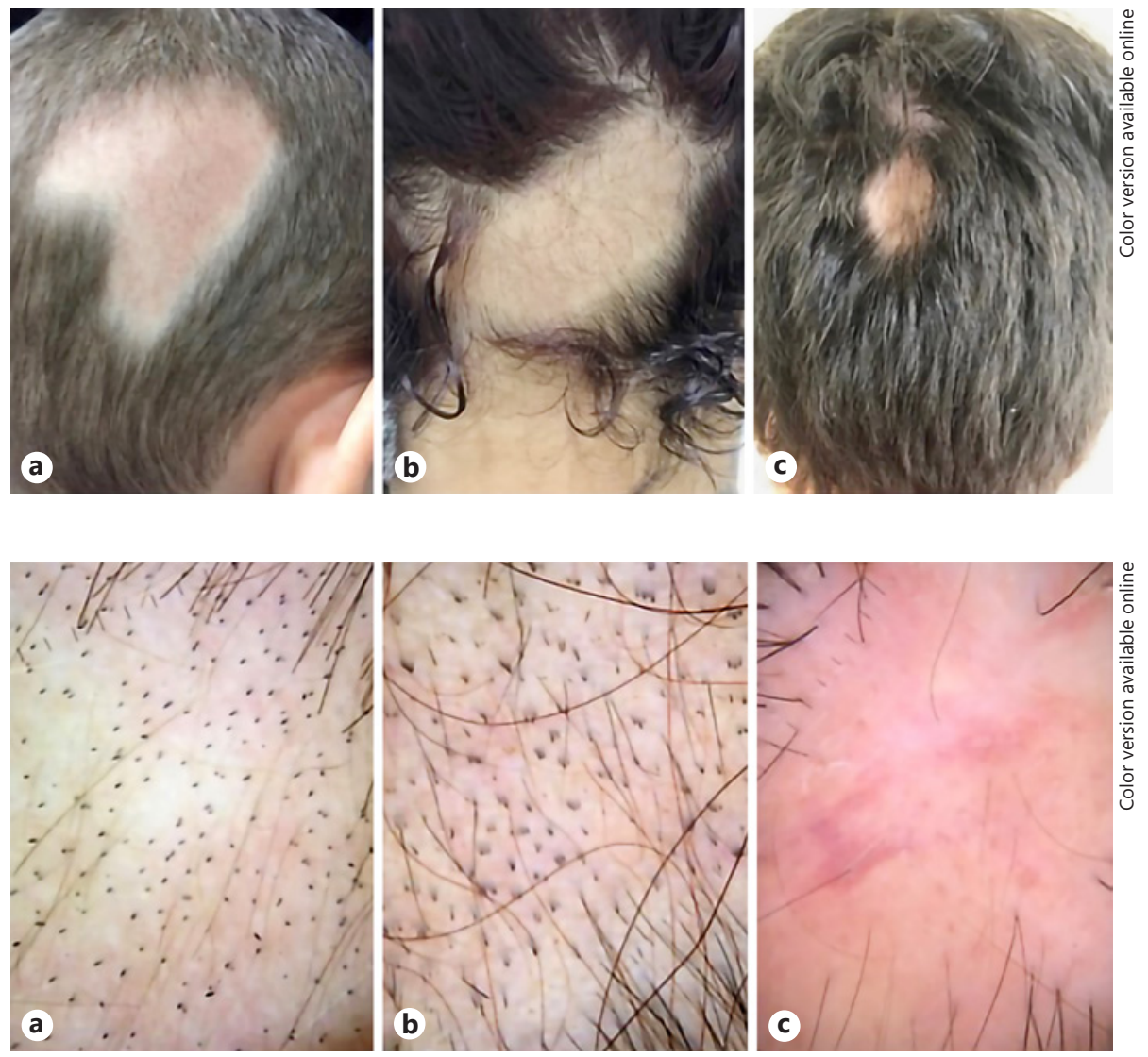

Presence of Thin Hairs in PressureInduced Alopecia
Skin Appendage Disord 2020;6:48-51 DOI: $10.1159 / 000504233$ 


\section{Case 3}

A 33-year-old Caucasian man was admitted to the ICU due to pneumocystosis related to AIDS and other complications, such as parvovirus hemolytic anemia and herpesvirus corneal ulcers. $\mathrm{He}$ was in an induced coma for about 20 days and, a few weeks after hospitalization, presented alopecia patches, some of them showing ulcero-crusted areas. Some patches had spontaneous regrowth in the following weeks; however, other lesions were persistent, mostly the ones that presented ulcero-crusted areas. On physical examination, 6 months after initial hospitalization, he had a welldelimited patch of alopecia in the occipital region, measuring about $3 \times 2.5 \mathrm{~cm}$ (Fig. 1c). The hair pull test was negative in the lesion and its periphery. Trichoscopy showed erythema, a whitish cicatricial area, vellus and residual thin hairs, and normal terminal hairs (Fig. 2c). A biopsy was performed, and histopathology showed 15 miniaturized hair follicles, absence of terminal follicles, and absence of inflammatory infiltrate.

\section{Discussion}

PA is a well-known type of physical alopecia with a circumscribed pattern of hair loss, which was first described in 1959 after long-lasting gynecological surgeries. Subsequently, it has been reported after other protracted surgical procedures, prolonged hospitalization in the ICU, and even after wearing tight orthodontic headgear $[7,8]$. It can occur in both adults and children, usually 3-28 days following the trigger events, and the occiput is the most commonly affected area [3,9].

The main etiological factor of this condition is the pressure-induced obstruction of the capillary blood flow in the skin, resulting in ischemia and localized hypoxemia of compressed hair follicles $[4,7,9]$. The duration of the pressure seems to be more relevant than its intensity. Surgeries that last over $4 \mathrm{~h}$, Trendelenburg position, obesity, psychiatric disorders, intraoperative hypoperfusion, acidosis, and performance status are some risk factors $[1,4$, 10]. Prognosis is often good, with complete resolution of alopecia in about $90 \%$ of cases $[1,11]$.

The skin hypoxia influences the clinical findings [6]. Mild decreases in papillary blood flow affect the hair bulb activity, resulting in localized anagen effluvium, similar to alopecia areata (AA), and this can be the only presenting feature. However, tenderness, erythema, swelling, and/or crusting usually precede hair loss and lead to skin necrosis and ulceration in patients who have been exposed to severe levels of hypoxia $[6,7,9]$.

Although there are few reports in the literature regarding trichoscopic features of PA, the main findings are nonspecific and include black dots, broken hairs, erythe-

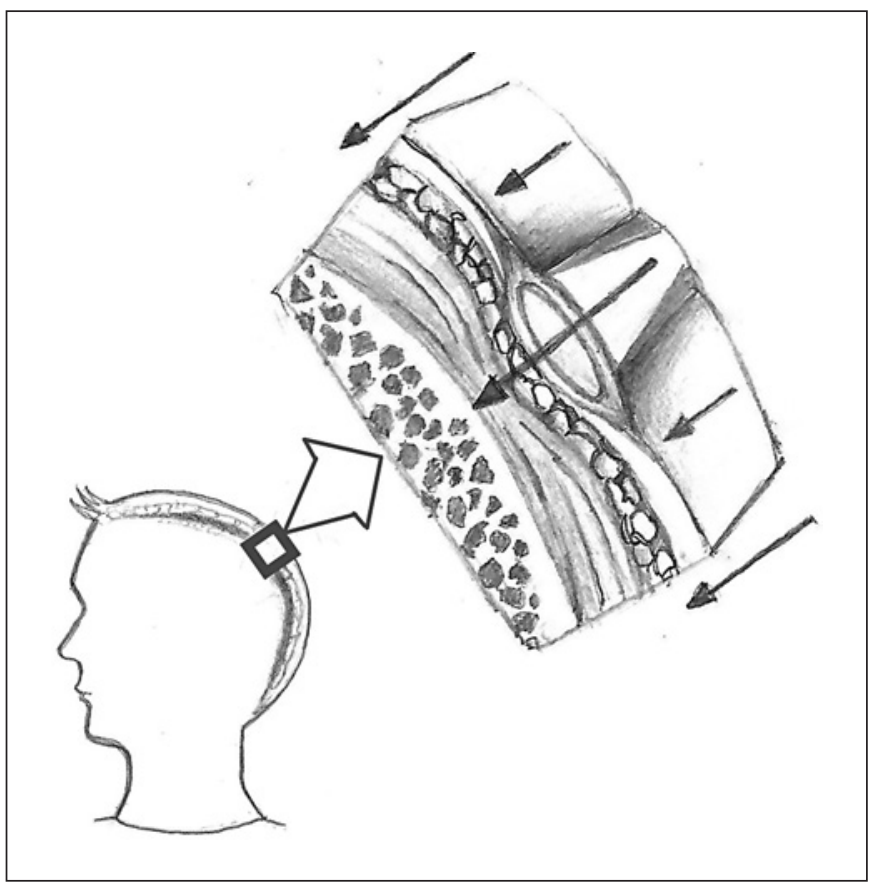

Fig. 3. Iceberg theory on the scalp: the pressure distribution occurs in a conical shape, similar to what happens in pressure ulcers, so it exposes deeper tissues to a higher pressure, leading these areas to suffer more from ischemia.

ma, and ulcerations $[3,4,6]$. Ravaioli et al. [11] suggest considering circle hairs as a favorable prognostic finding of reversible PA. Nonetheless, when erythema and ulcerations are absent, trichoscopy can mislead, resembling AA or trichotillomania [4]. Presence of yellow dots and exclamation mark hairs favors the diagnosis of AA [3]. Patches with a bizarre shape, such as presented in case 1, may also be mistaken as trichotillomania. Trichoscopy has a role in differentiating them, in which the finding of numerous broken hairs with the same length makes pressure the most probable cause.

In 2 of the cases presented, similar to what is found in the literature, trichoscopy showed erythema, black dots, and broken hair. However, the presence of many vellus and thin residual hairs in the patches of all cases must be acknowledged. Vellus hair is nonmedullated and hypopigmented, less than $3 \mu \mathrm{m}$ thick and less than $3 \mathrm{~cm}$ long, corresponding to about $10 \%$ of normal hair. Thin hair is a medullated terminal hair, over $3 \mathrm{~cm}$ long but less than $3 \mu \mathrm{m}$ thick, and may account for up to $20 \%$ of the total hair [12].

We hypothesize that one possible explanation why these follicles were preserved would be the lower meta- 
bolic rate of their smaller bulbs, making them suffer less from local hypoxia. Another reason would be that the pressure distribution occurs in a conical shape, similar to what happens in pressure ulcers, so it exposes deeper tissues to a higher pressure, leading these areas to suffer more from ischemia (iceberg theory) [13] (Fig. 3). Since terminal hair bulbs are located lower than the vellus ones, they will experience a greater injury and hypoxia, leading to loss of those hair shafts.

Scalp biopsy in PA is controversial in the literature since its histopathology is nonspecific $[1,4,14]$. Vascular thrombosis, necrosis of hair bulb cells, peribulbar lymphocytic inflammation, trichomalacia, an increased number of catagen and telogen follicles, panniculitis and pigment casts without peribulbitis are the most common features $[6,9,15]$.

In 2 of our cases, it was unnecessary to ask for a histopathological examination. The clinical findings, the history of a surgical procedure preceding the hair loss, and the trichoscopic findings showing no other cause of alopecia helped to confirm the diagnosis. Most cases of PA present spontaneous hair regrowth within 1-4 months, but patients who experienced more than $24 \mathrm{~h}$ of immobilization and/or presented ulcerations and necrosis from the onset of the disease can evolve with scarring alopecia, as seen in case $3[6,16]$. Treatment with topical corticosteroids might be useful in early stages, when erythema is present. Minoxidil may be used as adjuvant treatment. The exact role of corticosteroids and minoxidil still needs to be further investigated $[11,16]$. Preventive measures include intermittent head repositioning at half-hour intervals and intraoperative scalp massage. Avoidance of using hard or semi-hard gel headrests and replacement with soft pillows should be considered to reduce the incidence of PA, although it is impossible to know which patients will develop it $[5,16]$.

\section{Conclusion}

We reported 3 cases of PA in which clinical and trichoscopic features led to a correct diagnosis. Many vellus hairs and residual thin hairs were observed in all cases, and their presence may be explained by their lower metabolic rates and/or the more superficial insertion of their bulbs. These trichoscopic features have not yet been reported in the literature. Although more studies with a larger number of patients are necessary to confirm our observations, we suggest that they should be considered as trichoscopic clues for PA diagnosis in doubtful cases.

\section{Statement of Ethics}

Subjects have given their consent to publishing details and photos of the cases.

\section{Disclosure Statement}

The authors declare no conflicts of interest.

\section{References}

1 Davies KE, Yesudian P. Pressure alopecia. Int J Trichology. 2012 Apr;4(2):64-8.

2 Loh SH, Lew BL, Sim WY. Pressure alopecia: clinical findings and prognosis. J Am Acad Dermatol. 2015 Jan;72(1):188-9.

3 Ozdemir EE, Güleç AT. Clinical evaluation of postoperative pressure-induced alopecia using a hand-held dermatoscope. Int J Dermatol. 2014 Apr;53(4):e309-10.

4 Papaiordanou F, da Silveira BR, Piñeiro-Maceira J, Pirmez R. Trichoscopy of noncicatricial pressure-induced alopecia resembling alopecia areata. Int J Trichology. 2016 AprJun;8(2):89-90.

5 Chang ZY, Ngian J, Chong C, Chong CT, Liew QY. Postoperative permanent pressure alopecia. J Anesth. 2016 Apr;30(2):349-51.

6 Sano DT, Kakizaki P, Anzai A, Donati A, Valente NY, Romiti R. Headband pressure alopecia: clinical, dermoscopy, and histopathology findings in four patients. Int J Dermatol. 2018 Feb;57(2):237-9.
7 Thiem A, Kütt S, Hamm H. 'Television alopecia': a rare cause of pressure alopecia. J Eur Acad Dermatol Venereol. 2016 Mar;30(3): 504-5.

8 Khokhar RS, Baaj J, Alhazmi HH, Dammas FA, Aldalati AM. Pressure-induced alopecia in pediatric patients following prolonged urological surgeries: the case reports and a review of literature. Anesth Essays Res. 2015 SepDec;9(3):430-2.

9 Siah TW, Sperling L. The histopathologic diagnosis of post-operative alopecia. J Cutan Pathol. 2014 Sep;41(9):699-702.

10 Lee C, Choi PD, Scott G, Arkader A. Postoperative alopecia in children after orthopaedic surgery. J Pediatr Orthop. 2012 Oct-Nov; 32(7):e53-5.

11 Ravaioli GM, Starace M, Alessandrini AM, Guicciardi F, Piraccini BM. Pressure alopecia in pediatric and adult patients: Clinical and trichoscopic findings in 12 cases. J Am Acad Dermatol. 2019 Oct;81(4):1021-1023.
12 Rudnicka L, Rakowska A, Olszewska M, Slowinska M, Czuwara J, Rusek M, et al. Hair shafts. In: Rudnicka L, Olszewska M, Rakowska A, editors. Atlas of trichoscopy - Dermoscopy in hair and scalp disease. 1st ed. London: Springer; 2012. pp. 11-46.

13 Bauer J, Phillips LG. MOC-PSSM CME article: pressure sores. Plast Reconstr Surg. 2008 Jan;121(1 Suppl):1-10.

14 Domínguez-Auñón JD, García-Arpa M, Pérez-Suárez B, Castaño E, Rodríguez-Peralto JL, Guerra A, et al. Pressure alopecia. Int J Dermatol. 2004 Dec;43(12):928-30.

15 Sperling LC, Cooper SE, Knopp EA. Postoperative (pressure-induced) alopecia. In: Sperling LC, Cooper SE, Knopp EA, editors. An atlas of hair pathology with clinical correlations. 2nd ed. Florida: CRC Press; 2014. pp. $72-4$.

16 Goodenough J, Highgate J, Shaaban H. Under pressure? Alopecia related to surgical duration. Br J Anaesth. 2014 Aug;113(2):306-7. 